\title{
DROWNING PREVENTION PROGRAMME IN NORTHERN IRAN-A CLOSER LOOK AT THE PROBLEM
}

doi:10.1136/injuryprev-2012-040580a.14

${ }^{1}$ A Davoudi- kiakalayeh*, ${ }^{2} \mathrm{R}$ Mohammadi*, ${ }^{1} \mathrm{~S}$ Yousefzade-chabok. ${ }^{1}$ Trauma research center, Guilan University of Medical Science, IRAN; ${ }^{2}$ Division of Social Medicine, Department of Public Health Science, Karolinska Institutet, Sweden

Background Drowning has not been well recognised as a public health problem in many developing countries including Iran.

Aims This work outlines the context of the programme; describes its design and implementation; and reviews key findings that emerged from the evaluation drowning prevention programme in northern Iran.

Methods This article is complied based on cross-sectional study and two intervention study. Data for studies were derived from Death Registry System, Forensic Medicine, Weekly Report and household surveys. This project were located in border of Caspian Sea in northern Iran. Age group, gender, place and date of occurrence, external causes were assessed. Evaluation of the drowning prevention programme in the form of a quasiexperimental study and employed (1) pre and post interventional observations with a comparison community in a water recreational area of the Caspian Sea in northern Iran and (2) pre and post interventional observations without a comparison community in a rural area near the Caspian Sea coastline.

Results The risk of fatality resulting from drowning was observed to be greater during the preimplementation period than throughout the implementation period $(\mathrm{OR}=1.65)$. The drowning prevalence in rural areas of the Caspian Sea coastline as compared to a WHO standardised population demonstrated a continuous decrease in the age specific drowning rate among the oldest victims with a gradual decline during implementation.

Significance This effort suggests that the drowning prevention programme based on community based health promotion could help to both reduce the burden of drowning fatality and its related healthcare expenditure. 